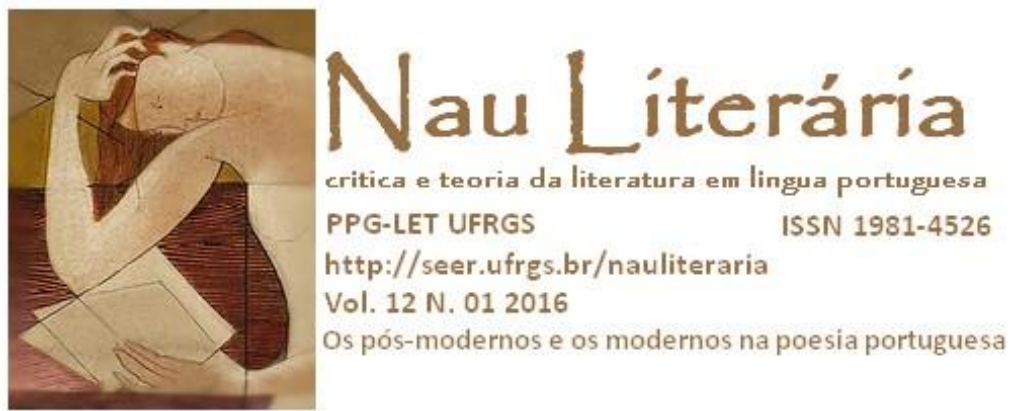

\title{
VOLTAR AO PRINCÍPIO DOS PRINCÍPIOS: REVISÃO CRÍTICA DO PASSADO E AFIRMAÇÃO DA TRADIÇÃO EM UALALAPI
}

\section{RETURNING TO THE BEGINNING OF BEGIINNINGS: CRITICAL REVIEW OF THE PAST AND AFFIRMATION OF THE TRADIDION IN UALALAPI}

\author{
Carina Marques Duarte ${ }^{1}$
}

\begin{abstract}
RESUMO: A proposta deste trabalho é verificar, através da análise da representação da personagem Ngungunhane, no romance Ualalapi do escritor moçambicano Ungulani Ba Ka Khosa, como ocorre a revisão crítica da história. Ao mesmo tempo, investigar-se-á o efeito de duas estratégias da FRELIMO - a conversão de Ngungunhane em herói nacional e o alheamento às tradições - na construção de uma identidade e em que medida Ualalapi se opõe a essa identidade forjada.
\end{abstract}

Palavras-chave: Ualalapi; Ngungunhane; Memória; Tradição; Identidade.

ABSTRACT: The purpose of this work is to verify, through the analysis of the representation of the character Ngungunhane, in the novel Ualalapi of the Mozambican writer Ungulani Ba Ka Khosa, how the critical review of history occurs. At the same time, the effect of two FRELIMO strategies - the conversion of Ngungunhane to a national hero and alienation from traditions - will be investigated in the construction of an identity and to what extent Ualalapi opposes to this forged identity.

Keywords: Ualalapi; Ngungunhane; Memory; Tradition; Identity.

\section{Considerações iniciais}

\footnotetext{
${ }^{1}$ Doutora em Literatura Comparada pela Universidade Federal do Rio Grande do Sul. Autora dos livros Do criador de civilização ao eu-abismo: uma leitura palimpsestuosa do Fausto de Fernando Pessoa (2014) e Álvaro de Campos, um seguidor decadente de Whitman e Nietzsche (2017). Atualmente, realiza estudos de pósdoutoramento em Literaturas Africanas de Língua Portuguesa.
} 
Desde Ualalapi - romance publicado em 1987 e que, além de ter rendido ao seu autor o Grande Prêmio da Ficção Moçambicana, foi colocado entre os 100 melhores livros da literatura africana do século XX -, a obra de Ba Ka Khosa questiona o passado de Moçambique, encarando-o a partir de uma perspectiva diversa da oficial, e reflete sobre a nação. Por esse aspecto, acompanha a trajetória das literaturas africanas de língua portuguesa, as quais, como observa Inocência Mata (2000), têm sido marcadas por uma consciência que evoluiu da sua condição nacionalista e agora sente a necessidade de repensar o país.

O romance Ualalapi $^{2}$ aborda a figura de Ngungunhane, imperador nguni que, no século XIX, submeteu os tsongas e colonizou o sul de Moçambique. Último resistente à ocupação portuguesa depois da decisão da Conferência de Berlim, Ngungunhane passou à história colonial portuguesa como símbolo da derrota dos negros de Moçambique. Entretanto, em 1975, com a independência, Ngungunhane foi alçado à categoria de herói nacional, reconhecido pelo governo da FRELIMO como o primeiro resistente moçambicano.

Em 1983, Samora Machel, presidente de Moçambique, requisitou ao governo português os restos mortais de Ngungunhane, argumentando sobre a importância da repatriação dos mesmos para a identidade nacional. Em 1985, em cerimônia solene, a urna funerária do último imperador de Gaza foi exposta no Salão Nobre do Conselho Executivo de Maputo.

Intrigado com a política de enfatizar Ngungunhane como herói nacional, Ungulani Ba Ka Khosa decidiu pesquisar acerca da vida daquele personagem histórico. O resultado de tais pesquisas está em Ualalapi, texto no qual o imperador nguni é retratado como ele realmente foi: um ditador estrangeiro, prepotente, que escravizou parte do território moçambicano, causando sofrimento inclusive para as pessoas que ele, na condição de rei, deveria proteger.

\section{Ngungunhane e a formação do Império de Gaza}

Recuperar a história de Ngungunhane equivale a recuperar a história do império de Gaza - maior da África no século XIX, que se estendia entre os rios Incomáti, ao sul, ao rio Zambeze, a norte, e do Oceano Índico, a leste, ao rio Save, a oeste. Controlado pela dinastia de Jamine, de ngunis ou vátuas (ramo dos zulus proveniente da África Austral), à qual pertencia Ngungunhane, o império de Gaza corresponderia hoje a mais de metade do território

\footnotetext{
2 O romance é composto por seis capítulos, que funcionam como unidades independentes, mas, ao mesmo tempo, interdependentes. Cada narrativa é precedida de um pequeno texto intitulado "Fragmentos do fim". Ngungunhane surge como protagonista somente no último capítulo.
} 
de Moçambique, a uma parte do Zimbabwe e da União Sul-Africana; dele faziam parte as etnias bitongas, chopes, cossas, landins e tsongas, numa população que, segundo Maria da Conceição Vilena (1996), variava de 500 mil a 2 milhões de habitantes.

Na década de 20 do século XIX, alguns chefes militares migraram da África Austral para o litoral; entre eles estava Sochangana, mais tarde Manicuse, avô de Ngungunhane. Sochangana se fixou entre os rios Limpopo e Save, atual território de Moçambique, onde, de acordo com Garcia (2008), subjugou cerca de 200 régulos e afrontou interesses locais de ingleses e portugueses.

Manicuse submeteu ao seu domínio todas as populações vizinhas, as quais, para não serem dizimadas ou acossadas, se resignavam com o pagamento de impostos que incluíam entrega de homens, gado, dinheiro, marfim, peles e utensílios agrícolas. Todo o sul de Moçambique sofreu com as incursões dos ngunis capitaneados por Manicuse, uma vez que as mesmas sempre resultavam em mortes, roubos e destruições.

Tampouco foi fácil o relacionamento dos portugueses, há tempo presentes na região, com os súditos de Manicuse. Por conta disso, e também para diminuir as pretensões do avô de Ngungunhane, o governo português enviou, em 1840, uma embaixada à corte daquele chefe tribal.

A morte de Manicuse, em 1858, acarretaria uma disputa pelo trono entre os filhos Mawewe e Muzila. O segundo, tendo recebido dos portugueses cerca 2.000 espingardas, 50 mil cartuchos e 1.200 pederneiras, conseguiu derrotar o irmão no final do ano de 1861 e tornar-se o régulo do império de Gaza.

A sucessão de Muzila, quando da sua morte em 1884, também foi problemática. Na ocasião - como nos mostra Ualalapi - Mudungazi, mais tarde autodenominado Ngungunhane, assume o trono depois de ordenar a morte do primogênito Mafemane. Durante 11 anos, até 1895, Ngungunhane governou os ngunis com poder absoluto, "que passaria por uma política de rapina, lançamento indiscricionário de impostos, espionagem e nepotismo" (GARCIA, 2008, p. 134). Com as tribos, mantinha frequentemente relações inamistosas. Com as autoridades portuguesas, a princípio, procurou manter alguns contatos, tanto que, nos seus primeiros dias na condição de soberano de Gaza, enviou emissários a Chiloane a fim de comunicar sua entronização às autoridades portuguesas. Tal fato causou tão boa impressão nas mesmas autoridades, que propuseram a Ngungunhane a assinatura de acordos de vassalagem. Assim, representantes do chefe nguni foram enviados a Lisboa com o propósito de firmar um documento diplomático, através do qual Ngungunhane comprometia-se, entre 
outras coisas, a aceitar a abertura de escolas e missões em territórios sob a sua influência, a vinda de um representante luso para residir em sua corte e não declarar guerra aos régulos de outros grupos étnicos sem o prévio consentimento de Portugal. Convém salientar que o referido acordo ficou somente no papel, pois jamais levou Ngungunhane a esperar a autorização portuguesa para atacar, incendiar aldeias e extorquir bens de outras tribos.

Ademais, o início do reinado de Ngungunhane coincidiu com o momento em que, na sequência da Conferência de Berlin (1886), discutia-se a questão da ocupação da África. E Ngungunhane, percebendo o interesse de outras potências pelo território, não se limitou a negociar apenas com Portugal. Desse modo, como menciona Garcia (2008), ora aliou-se aos portugueses para reforçar o domínio sobre outros regulados rivais e ainda para se proteger das ambições inglesas, ora negociou com a Grã-Bretanha para desacreditar as cláusulas dos acordos de vassalagem aos quais se submetera em 1885.

Representantes da British South Africa Company faziam-se cada vez mais presentes na corte nguni com o objetivo de, em troca de armas e dinheiro, obter favores na concessão de terrenos para a exploração de minérios e a livre circulação para o litoral Índico. Por outro lado, de acordo com Garcia (2008), os portugueses, ao norte, pressionavam o chefe nguni para ter o controle das minas de Manica, fato que levou Ngungunhane a transferir a capital do reino de Mossurize para Manjacase.

Ao mesmo tempo em que pressionava os nativos, Portugal também sofria pressões, como comprova o Ultimato inglês de 1890, que o forçou a retirar as tropas do Chire (atual Malawi) e dos Macololos e da Machona (atual Zimbabwe). Tal acontecimento levou a que portugueses e ingleses firmassem, em 1891, um acordo sobre a delimitação de Moçambique, ficando os territórios ngunis na possessão portuguesa. Em virtude disso, Ngungunhane não pôde mais valer-se da ambiguidade diplomática para desobedecer aos acordos feitos com Portugal.

Em 1894, devido a excessos das autoridades coloniais na cobrança de impostos, segundo Garcia (2008), alguns régulos tsongas revoltaram-se e cercaram Lourenço Marques durante dois meses. A fim de evitar maiores prejuízos, as autoridades portuguesas enviaram oficiais a Moçambique com o objetivo de constituir um exército, que deveria combater os chefes tradicionais, os quais, naquele momento, estavam sob a tutela de Nghungunhane. Tal exército enfrentou e venceu os tsongas em fevereiro de 1895.

Contudo, dois régulos tsongas conseguiram fugir e buscaram abrigo junto à corte do leão de Gaza, que se recusou a entregá-los aos portugueses. Diante disso, o comissário 
Antonio Enes resolveu ocupar Gaza, e, em novembro de 1895, as suas tropas impuseram aos ngunis uma dura derrota. Depois deste episódio, Ngungunhane abandonou Manjacaze, a capital do império, e dirigiu-se para Chaimite, de modo que o Coronel Galhardo entrou sem qualquer resistência em Manjacaze.

O capitão Moutinho de Albuquerque dirigiu-se a Chaimite ao encontro de Ngungunhane. Lá, em 28 de dezembro de 1895, efetuou a prisão do último líder do império de Gaza; em seguida, o conduziu, juntamente com o séquito que o acompanhava - do qual faziam parte as sete mulheres e o filho primogênito -, para Lourenço Marques.

Em 13 de janeiro de 1896, Ngungunhane foi posto em um navio a caminho de Lisboa, onde, dois meses depois, como refere Garcia (2008), foi recebido triunfalmente como troféu de guerra. Seu destino final, a cumprir-se meses mais tarde, seria o exílio nos Açores. Na Ilha Terceira, o ex-régulo de Gaza foi alfabetizado, batizado, se tornou alcoólatra e viveu onze anos, tendo morrido, em 1906, triste e na solidão.

\section{Revisão crítica do passado e afirmação das tradições}

O primeiro fato histórico abordado em Ualalapi é a morte de Muzila, acontecimento pressagiado pelos dois pangolins - animais de mau agouro - encontrados pelo guerreiro Ualalapi e seus comandados durante uma expedição de caça. Temerosos, os guerreiros começam a pensar em suas esposas e filhos. Ao retornarem à aldeia, ficam sabendo da morte do superior, à qual se seguiram outras, pois, segundo a crença local, quando um rei morria, alguns súditos deveriam acompanhá-lo.

Mudungazi reúne os guerreiros e relembra a construção do império pelo avô, a guerra sucessória entre Mawewe e o sucessor indicado por Manicuse, Muzila, e conclui afirmando que fora escolhido pelo pai para ser o novo régulo de Gaza e que, por isso, não admitirá partilhar o poder:

Não vou partilhar o poder. Ele pertence-me desde que nasci do ventre de Lozio, minha mãe, a mulher preferida de Muzila. E serei temido por todos, porque não me chamarei Mudungazi, mas Ngungunhane, tal como essas profundas furnas onde lançamos os condenados à morte! O medo e o terror ao meu império correrão séculos e séculos e ouvir-me-ão em terras por vocês nunca sonhadas! (BA KA KHOSA, 2013, p. 25-26).

Com efeito, o medo e o terror seriam marcas do comando do leão de Gaza, e a sua figura despertaria ódio inclusive entre os súditos, detalhe que foi explorado por Ba Ka Khosa em Ualalapi através da personagem Domia, filha de Mputa. 
Acusado de assédio sexual pela primeira esposa do régulo, Mputa fora condenado à morte. Todavia, na iminência do cumprimento da sentença, o guerreiro solicitou que fosse submetido à prova do mondzo e bebeu do veneno sem pestenejar, de maneira que a sua inocência ficou comprovada. Ainda assim, Ngungunhane ordenou o seu sacrifício, acusandoo de feitiçaria.

Domia, que presenciara o julgamento e a injusta condenação do pai, alimentou durante anos o desejo de vingança e, chegada a hora, pôs em prática o seu plano de seduzir e matar o soberano nguni. Sua estratégia, porém, resultou falha, pois, descoberta nas suas secretas intenções, Domia foi violentada por Ngungunhane e, em seguida, morta pelos guardas, sem que tivesse causado maior dano ao rei que um corte na coxa direita e o ultraje de ser cuspido e chamado de cão por uma mulher.

Ao final dos dois primeiros capítulos do romance, fica a ideia de que a morte de dois guerreiros e súditos fiéis foi consequência das ordens e da intransigência de Ngungunhane. Na perda de Ualalapi ${ }^{3}$ e no sacrifício de Mputa já estariam presentes germes da decadência, cujo clímax seria o aprisionamento do régulo pelas tropas portuguesas.

Convém mencionar aqui o conto “Quem manda aqui?”, de Paulina Chiziane, no qual o imperador nguni é apresentado como um chefe prepotente, arrogante e intolerante, que se sente o grande criador $^{4}$, contempla o que está à sua volta e vê tudo como obra sua. Este homem orgulhoso e prepotente não suportaria qualquer enxovalho na sua imagem. Por isso, quando uma andorinha defeca em seu olho durante o rotineiro cochilo, é tomado pela fúria, chama os guerreiros e lhes ordena que lhe tragam as andorinhas a fim de que lhes aplique um castigo exemplar: "silenciem todas as andorinhas. Apanhem-nas. Tragam-nas aqui ao castigo, para que todas as aves do mundo saibam quem manda aqui!” (CHIZIANE, 2013, p. 11). Apesar de duvidar de que o imperador esteja no uso da razão, o general cumpre as ordens e organiza uma expedição. Com a partida dos melhores guerreiros, o reino fica desprotegido.

\footnotetext{
${ }^{3}$ Contrariando o pedido da esposa para que não matasse Mafemane, Ualalapi dispara a lança. Após cumprir a missão dada pelo leão de Gaza, abalado, Ualalapi corre em direção à floresta, na qual desaparece. "Minutos depois o choro de uma mulher e de uma criança juntaram-se ao não e ao ruído da floresta a ser arrasada. E o mesmo ruído cobriu o céu e a terra durante onze dias e onze noites, tempo igual à governação, em anos, de Ngungunhane" (BA KA KHOSA, 2013, p. 34). A equivalência na duração, em dias, do ruído da floresta, do grito lancinante de Ualalapi e do choro da sua esposa e do filho (que choram durante onze dias e morrem afogados pelas lágrimas) com o tempo de reinado de Ngungunhane, em anos, sugere que ali começava um sofrimento que persistiria.

4 "Contempla a sua obra e suspira de orgulho - fui eu quem transformou tudo isto em vida. coloquei luz nos olhos dessa gentalha. Quando aqui cheguei, a terra era selvagem e era macho. Domestiquei-a. Tornei-a fêmea, é toda minha, faço o que quero. Dá-me bons frutos, cereais, gado. Dá-me sol e chuva. Nessa terra fêmea, os homens me servem de joelhos, porque já não são homens. Sou o único macho na superfície da terra" (CHIZIANE, 2013, p. 9).
} 
Em seguida, o rei dos rongas, envolvido em querelas com os portugueses, pede abrigo a Ngungunhane, que, contrariando os conselheiros, dá acolhida a Matibyana ${ }^{5}$. O resultado é o ataque perpetrado pelos portugueses e a queda do império.

Importa referir que a escritora Paulina Chiziane é de origem chope, povo que estava entre os principais inimigos de Ngungunhane ${ }^{6}$. Ungulani Ba Ka Khosa, por sua vez, pertence à etnia tsonga, submetida pelos ngunis no sul de Moçambique. Desse modo, percebe-se que Ngungunhane, embora tenha sido uma figura emblemática da história africana, não é unanimidade, uma vez que não representava os interesses de todas as etnias locais.

Contudo, a partir da década de 1960, com o movimento independentista, houve um esforço da FRELIMO, ampliado depois da independência, no sentido de converter Ngungunhane em herói nacional. Naquele momento, dez anos depois da libertação de Portugal, quando o partido no poder enfrentava a RENAMO na Guerra Civil - acontecimento que ameaçava fraccionar a integridade do país - segundo Garcia (2008), era necessário recorrer aos ritos de recordação que permitissem perpetuar o sentido de pertença e continuidade.

No texto "Memória, esquecimento, silêncio", Michel Pollak (1989) salienta a força dos diferentes pontos de referência - entre os quais, as tradições, os costumes, as datas e os personagens históricos - que estruturam nossa memória e a inserem na memória da coletividade à qual pertencemos. A memória coletiva, ao definir o que é comum a um grupo e o que o diferencia dos outros, fundamenta e reforça o sentimento de pertencimento e as fronteiras socioculturais. Segundo Pollak, as memórias coletivas, fortemente constituídas, como é o caso da nacional, têm uma função:

\begin{abstract}
A memória, essa operação coletiva dos acontecimentos e das interpretações do passado que se quer salvaguardar, se integra, como vimos, em tentativas mais ou menos conscientes de definir e de reforçar sentimentos de pertencimento e fronteiras sociais entre coletividades de tamanhos diferentes: partidos, sindicatos, igrejas, aldeias, regiões, clãs, famílias, nações etc. A referência ao passado serve para manter a coesão dos grupos e das instituições que compõem uma sociedade, para definir seu lugar respectivo, sua complementariedade, mas também as oposições irredutíveis (POLLAK, 1989, p. 9).
\end{abstract}

Há uma relação íntima entre memória e identidade:

A memória é um elemento constituinte do sentimento de identidade, tanto individual como coletiva, na medida em que ela é também um fator extremamente importante do sentimento de continuidade e de coerência de uma pessoa ou de um grupo em sua reconstrução de si (POLLAK, 1992, p. 204).

\footnotetext{
5 Garcia (2008) refere que dois régulos tsongas - Matibejana e Mahazul - se refugiaram na Corte de Ngungunhane.

${ }^{6}$ Sublinhemos que a personagem sofre uma transformação no conto de Chiziane, passando de arrogante, tirano e inconsequente imperador a, no final, representante espiritual das lutas pelos interesses moçambicanos, pela liberdade.
} 
Nesse sentido, a mitificação ${ }^{7}$ de Ngungunhane, ponto de referência comum aos habitantes, tinha a função de reforçar a consciência nacional - uma vez que o chefe nguni fora, em certa medida, um resistente às imposições coloniais - e fomentar o sentimento de identidade. O problema é que o intento da FRELIMO envolvia a imposição de uma determinada visão do passado, e é a isso que Ungulani Ba Ka Khosa reage em Ualalapi. Utilizando o que Inocência Mata (2000) definiu como estratégia contradiscursiva - cujo objetivo é a deslegitimização de um projeto de nação monocolor pensado sob o signo da ideologia nacionalista -, Ba Ka Khosa demonstra que a história oficial estava eivada por nacionalismos baratos. Importa salientar que ele considerava reducionista a tentativa de pautar os referentes dos moçambicanos sob a batuta do nacionalismo, ou seja, um renascimento do ponto de vista de referências políticas e não culturais, sobretudo porque, ainda de acordo com o escritor, a sustentabilidade de uma cidadania amarrada ao político e não ao cultural é extremamente fraca, tênue.

Contrário à cidadania presa ao político, que resultaria da faina ideológica do discurso oficial, Ba Ka Khosa permite a irrupção das memórias da margem, e, quando estas irrompem, conforme Pollak (1989), ocorre a revisão crítica do passado. Trata-se, aqui, de uma revisão através de uma metaficção historiográfica ${ }^{8}$ que questiona a versão da história propagada pelo discurso oficial, a grande narrativa da FRELIMO. Ao fazê-lo, no entanto, não fica limitada a um ponto de vista. Romance polifônico ${ }^{9}$, Ualalapi recusa uma resposta definitiva, o que pode ser observado nas epígrafes acerca de Ngungunhane, as quais contêm pareceres de Ayres

\footnotetext{
${ }^{7}$ Esta mitificação envolveu aquilo que Ricoeur (2007) denominou memória manipulada - caracterizada mediante fenômenos ideológicos, ou seja, de abusos que resultam da manipulação e do esquecimento. Trata-se de uma memória instrumentalizada.

${ }^{8} \mathrm{Na}$ obra Poéticas do pós-modernismo: história, teoria, ficção, Linda Hutcheon (1991) enfatiza que, a partir dos anos 1980, a historiografia oficial, que celebrava os grandes feitos de reis, governadores, generais, entre outros membros da elite colonial, passa a ser contestada no aspecto reflexivo, paródico, didático, irônico e intertextual. Essas narrativas, que são chamadas de "novo romance histórico" ou de "metaficção historiográfica", têm caráter metadiscursivo e recorrem ao tratamento crítico da tópica histórica tradicional e à desconfiança em relação às grandes narrativas.

${ }^{9}$ As várias vozes, vários pontos de vista, podem ser observados, por exemplo, em "Fragmentos do fim 3", cujo foco recai sobre o coronel Galhardo, que liderou a tomada de Manjacaze. Ungulani Ba Ka Khosa reproduz, através de citação direta, trechos do relatório redigido pelo militar acerca da marcha sobre a capital do império de Ngungunhane; traz, em seguida, através do narrador, fatos que o coronel omitiu - entre os quais: a profanação de locais sagrados, o roubo de cinco peles de leão, posteriormente ostentadas na metrópole como resultado de uma perigosa caçada em África, ter esventrado cinco negros com o objetivo de se certificar da dimensão dos seus corações e ter se mantido sereno diante de uma criança gatinhando em chamas. Por fim, reproduz o parecer do Comissário Régio de Moçambique, que louvava a bravura, a tenacidade, o respeito pelo homem, a bondade e o amor à pátria presentes no coronel Galhardo.
} 
d'Ornellas ${ }^{10}$ - que revela admiração pelo régulo - e do Dr. Liengne ${ }^{11}$ - que descreve o leão de Gaza como uma figura horrenda, cuja política era falsa, absurda e cheia de duplicidade.

No capítulo "Damboia", surge outro aspecto da personalidade de Ngungunhane. Aqui, em face da doença ${ }^{12}$ da tia e das suas trágicas consequências, o governante insiste em negar a realidade:

Ngungunhane andava de um lado para o outro, afirmando que tudo andava bem e que havia grandes progressos, pois as colheitas nunca vistas encheram celeiros de nunca acabar, e as crianças que nunca nasceram vieram ao mundo mais gordas e sãs, e os velhos duravam mais anos, e os guerreiros mais batalhas ganhavam, os que diziam o contrário eram pendurados em árvores" (BA KA KHOSA, 2017, p. 67).

Apesar dos revezes por que passava o império, Ngungunhane seguia afirmando uma prosperidade que existia somente no seu discurso vazio. E, em meio à adversidade, maiores eram o imperativo da hipocrisia e o autoritarismo do seu reinado.

Em que pese a tirania, a aparência física do soberano nguni revela degradação, uma degradação concomitante à ideia de ocaso do império, que, no final do capítulo "O diário de Manua" será ainda mais forte.

Manua, filho de Ngungunhane, era um assimilado. Em 1892, viajando no paquete Pungué de Moçambique para Lourenço Marques, contrariando o hábito secular dos ngunis, comeu peixe e bebeu um litro de vinho. Durante a noite, sonhou com serpentes que se enrodilhavam no corpo bojudo do pai. No fim da madrugada, acordou sobressaltado com as batidas na porta do seu camarote. Levantou e viu que havia vomitado, pois o chão estava estranhamente coberto por arroz, vinho e cabeças de peixes. O vômito saía do camarote e inundava toda a extensão do navio, o que levou o comandante a esbravejar que, se Manua não fosse filho do rei, o faria limpar tudo e ainda lançá-lo-ia para fora do navio. Abalado com o ocorrido, Manua pegou papéis e caneta e escreveu um desabafo, no qual sugere que o vômito fora decorrência de feitiço.

Um dos poucos em sua tribo a ter acesso ao mundo dos brancos, Manua escreve que, quando for imperador, eliminará as práticas adversas ao Senhor e que será dos primeiros, nas

\footnotetext{
${ }^{10}$ Militar português que participou das operações que levaram à captura de Ngungunhane e à queda do império de Gaza.

${ }^{11}$ Médico suíço que, em 1892, inaugurou um posto de saúde e missão evangélica em Manjacaze, capital do império de Ngungunhane, onde viveu quatro anos, exatamente no período em que o relacionamento dos ngunis com a autoridade colonial foi mais conturbado.

12 Damboia, tia do régulo, foi acometida por uma hemorragia que perdurou por meses. O seu sangue menstrual inundou a casa e atingiu o pátio. No segundo mês de ininterrupto sangramento, vieram as chuvas. Com isto, o sangue chegou ao rio, tingiu a água e matou os peixes que os ngunis não comiam. Em seguida, crocodilos passaram a viver nas margens do rio e era normal vê-los na soleira das portas. Alguns velhos suicidaram-se, outros, velhos e novos, morreram de sede, pois a água do rio estava contaminada e o lago das proximidades também.
} 
terras africanas, a aceitar e assumir os nobres costumes dos brancos ${ }^{13}$. Esta admiração pelos costumes dos brancos desagradava Ngungunhane a tal ponto que, de acordo com Manhune ${ }^{14}$, teria envenenado o filho.

Convém reparar, como salienta Ana Mafalda Leite (2012), que Manua concluiu o curso de artes e ofícios e deixou escrito um diário, o qual, como se tem conhecimento no início do capítulo, foi encontrado em meio aos escombros daquilo que fora a capital do império de Gaza. A descoberta do diário está, assim, associada ao declínio ${ }^{15}$ do império, uma vez que a escrita é o símbolo maior da desvalorização das tradições locais e que a sua introdução em uma sociedade de cultura oral gera um desequilíbrio. Não é por acaso que Manua, assimilado que transgride as tradições do povo nguni, é punido com a morte. Ao curvar-se à cultura dos europeus, o filho de Ngungunhane comete uma desmedida, conforme se pode inferir através dos testemunhos orais a que recorre o narrador:

Buinsanto, que se refugiara no Transvaal depois da queda do império, afirmou que seu irmão Manua
bebia com muita sofreguidão devido ao feitiço dos bisavôs que se irritavam por aqueles modos
estrangeiros no andar, no vestir e no falar. O pênis minguava de dia para dia. No dia de sua morte,
acordou sem nada entre as coxas e apanhou a maior bebedeira de sempre.
Manhune transmitira aos filhos e ao neto que Manua fora envenenado pelo pai, pois era uma vergonha
para os nguni ver um filho seu assimilar costumes de outros povos estrangeiros. E o pior, dizia
Manhune, Manua parecia um chope, pois era subserviente aos portugueses. Matem-no na próxima
oportunidade, disse Ngungunhana num dos encontros que teve com os maiores do reino (BA KA
KHOSA, 2013, p. 101-102). Ao mostrar que, sobrepondo a cultura estrangeira às tradições locais, Manua cometera uma infração grave e, portanto, na visão dos ngunis, passível de punição, e ao relacionar o diário com a decadência do império, Ungulani Ba Ka Khosa aponta para a importância da oralidade nas sociedades africanas. As narrativas orais funcionam como pilares onde se apoiam os valores e as crenças transmitidas pela tradição. São elas, nas sociedades tradicionais africanas, que transportam a herança das culturas locais por meio de exemplos que objetivam o fortalecimento dos laços entre os membros do grupo. Além de garantirem o entendimento do indivíduo acerca do seu lugar de pertença, as narrativas orais, segundo Laura Padilha, fazem circular

\footnotetext{
${ }_{13}$ Manua introjetou o discurso da superioridade dos brancos, discurso que se faz presente quando um dos passageiros diz ao comandante que a sujeira no navio é o resultado de terem admitido ali a presença de pretos: "O senhor acha que um branco como eu e outros que por aqui andam não sabem onde devem vomitar?" (BA KA KHOSA, 2013, p. 95) e "Se eu fosse rei tirava os portugueses dessas terras e deixava os pretos na sua vida selvagem, pois de nada nos vale estar aqui com histórias de civilização" (Ibdem, p. 98).

${ }^{14}$ Uma das vozes a que recorre Ungulani Ba Ka Khosa para dar conta do ocorrido com Manua depois do retorno à tribo.

${ }^{15}$ Algumas palavras reforçam a ideia de decadência, de fraqueza, de falta de vida, como é possível verificar na frase sobre as letras soltas no diário: "Juntando as cinco letras tem-se a palavra morte. Ou temor. Ou tremo" (BA KA KHOSA, 2013, p. 101).
} 
a carga simbólica da cultura autóctone, permitindo-se a sua manutenção e contribuindo para que esta mesma cultura possa resistir ao impacto daquela outra que lhe foi imposta pelo dominador brancoeuropeu e que tem na letra a sua mais forte aliada. A milenar arte da oralidade difunde as vozes ancestrais, procura manter a lei do grupo, fazendo-se, por isso, um exercício de sabedoria (PADILHA, 2007, p. 35).

Elemento constitutivo da identidade, as narrativas orais reforçam, nos indivíduos, a consciência da mesma. São, ademais, um meio de resistência.

A personagem Ngungunhane reage à subserviência do filho à cultura estrangeira. A sua resistência à dominação é também uma luta pela a manutenção das tradições nguni. Esta é uma das faces do imperador de Gaza reveladas por Ba Ka Khosa, que, ao fazê-lo, sugere a relevância das raízes locais e da tradição oral na constituição da identidade.

Feito prisioneiro pelas tropas portuguesas, Ngungunhane profere o último discurso para a multidão que o vaia. Prevê, então, a subjugação do povo através do poderio bélico e da escrita:

Estes homens da cor de cabrito esfolado que hoje aplaudis entrarão nas vossas aldeias com o barulho das suas armas e o chicote do comprimento da jiboia. Chamarão pessoa por pessoa, registrando-vos em papéis que enlouqueceram Manua e que vos aprisionarão. Os nomes que vêm dos vossos antepassados esquecidos morrerão para todo o sempre [...] (BA KA KHOSA, 2013, p. 115).

A escrita passaria o reger a vida dos homens, enquanto a palavra seria esquecida. Este foi um dos resultados do processo de sobreposição de culturas no qual se apoiou a colonização. Mas Ngungunhane vaticina outras consequências:

Fora das grades, os vossos netos esquecer-se-ão da língua dos seus antepassados, insultarão os pais e envergonhar-se-ão das mães descalças e ocultarão a casa aos amigos. A nossa história e os nossos hábitos serão vituperados nas escolas sob o olhar atento dos homens com vestes de mulher que obrigarão as crianças a falar da minha morte e a chamarem-me criminoso e canibal. As crianças rir-seão dessa vergonha que os velhos sem auditório tentarão redimir, dando a versão que ninguém escutará. (BA KA KHOSA, 2013, p. 119).

Ngungunhane prognostica, como parte da sobreposição de culturas, o esquecimento do passado e das línguas locais e a assunção da história portuguesa, ou da versão dos portugueses, a qual o qualificaria como criminoso.

Contra o branqueamento da historia previsto, na ficção, por Ngungunhane, reagiriam os integrantes da FRELIMO em um dos primeiros livros elaborados pelo Departamento de Educação e Cultura do partido, História de Moçambique, editado em 1971. Já na introdução da obra, os autores, considerando a significativa diferença entre a história do colonizador e a história do colonizado, reivindicam para si a história a que têm direito, que não seguisse o método ${ }^{16}$ até então vigente e que privilegiasse o ponto de vista dos moçambicanos.

\footnotetext{
16 Todas as histórias que têm sido escritas sobre Moçambique baseiam-se na acção que os portugueses exerceram sobre o nosso país. Com isto queremos dizer que a história de Moçambique até aqui tem sido um relato da
} 
Até a questão do apagamento da história dos moçambicanos o discurso de Ngungunhane se alinha aos preceitos defendidos pela FRELIMO. Todavia, Ungulani Ba Ka Khosa encarrega esta personagem, representação daquele a quem o partido concedera o status de herói nacional, de deslindar alguns dos efeitos do marxismo: "Mas começarão a aprender novas doutrinas que rejeitarão os espíritos, os feiticeiros e curandeiros" (BA KA KHOSA, 2013, p. 120).

Logo após a independência, a FRELIMO tratou de pôr em prática o seu projeto de, sobre os escombros da divisão étnica e as ruinas do Estado colonial, construir um Estado marxista-leninista. Para tanto, além de empreender a transformação das estruturas do poder colonial, reprimiu os valores tradicionais, o que teve, segundo Bouene (2005), consequências nefastas tanto para o governo - já que diminui a sua base de apoio - quanto para a sociedade - porque as comunidades perdem o equilíbrio psicológico.

Entre os bantos, o equilíbrio é alcançado através da harmonia com a terra e com os antepassados, e nisto as cerimônias religiosas têm grande importância. Ocorre que, em 1975, o governo decide extinguir a regedorias ${ }^{17}$, estruturas consideradas conflitantes com o poder popular. Ao mesmo tempo, eram eliminadas as chefias das sociedades tradicionais, sem uma análise profunda da questão. Em seguida, a fim de facilitar a produção coletiva e de desestruturar a organização tradicional das populações, o governo instaurou as aldeias comunais, o que forçou as pessoas ao abandono das suas casas e, por conseguinte, acarretou a perda dos símbolos, entre os quais estavam os locais de homenagem aos mortos, vistos pela FRELIMO como mostras de obscurantismo. Contudo, apesar do interdito ao culto à tradição, as pessoas continuaram recorrendo às autoridades tradicionais e seguiram realizando as cerimônias tradicionais clandestinamente: "mas pela noite a dentro muitos irão ao curandeiro e pedirão a raiz contra as balas do inimigo" (BA KA KHOSA, 2013, 120).

No afã de construir um Estado marxista, a FRELIMO impulsionou o alheamento às realidades culturais locais - previsto, na ficção, por Ngungunhane -, que Ba Ka Khosa (2010) viu, em certa medida, como resultado do medo de perder o chão da moçambicanidade, já que muitos temiam que falar em tradição equivalesse a falar em pretização das instituições, da

colonização portuguesa e, por isso, a partir da data em que eles chegaram a Moçambique. A história que fica antes dos portugueses é quase totalmente desconhecida. Ao iniciarmos o estudo da História de Moçambique, não poderíamos seguir o mesmo método. Como todos os outros povos do mundo, o povo moçambicano tem uma história. Assim, tentamos estudar a História de Moçambique sob um ponto de vista moçambicano, quer dizer, baseado na história do povo moçambicano (FRELIMO, apud GARCIA, 2008, p. 143).

17 As áreas indígenas estavam divididas em regedorias ou chefaturas e eram administradas pelos chefes tradicionais aliados do poder colonial. 
balcanização de um país que se conduz pelo princípio da universalidade e igualdade inscrita nos direitos, deveres e liberdades fundamentais, consagrados na Constituição. Para estes, falar da tradição significava um retrocesso, um nacionalismo redutor.

A postura acima referida, no entendimento de Ungulani Ba Ka Khosa, foi um fator determinante para que o Estado não conseguisse cumprir o seu papel de condutor à cidadania plena:

Moçambique não se encontrou. Devo dizer, embora existam teorias em contrário, que o papel do Estado é fundamental na libertação de iniciativas que conduzam à cidadania plena. E os primeiros anos de independência foram fulcrais na definição da pauta da nossa sinfonia cultural. Esmagamos as notas da diversidade, silenciamos as vozes que vinham das furnas do tempo e, movidos por pretensões ideológicas de difícil sustentação, tentamos erigir um corpo, permitam-me o empréstimo, sem ADN, incaracterístico, insosso, descolorido, de voz monótona, desenraizada, totalmente à deriva. Perdemos, na euforia da libertação, a oportunidade de libertar a memória e de traçar, com inteira liberdade, o nosso destino cultural (BA KA KHOSA, 2015, p. 129-130).

A ação de negligenciar a tradição (de silenciar as vozes provenientes das furnas do tempo) atende ao objetivo de construir uma identidade nacional. Neste ponto, convém lembrarmos Anthony Smith (1997), quando refere que a identidade nacional assenta tanto em uma identidade cultural quanto em uma identidade política, situando-se, assim, em uma comunidade cultural e em uma política. Havendo a sobreposição da segunda à primeira, o produto será, como observa Tutikian (2014), uma identidade forjada, o corpo insosso, incaracterístico, mencionado por Ba Ka Khosa.

Uma vez que a identidade construída é inautêntica, para que se possa chegar o mais próximo possível daquilo que o homem e a nação representam, faz-se necessária a reivindicação do resgate das raízes, da tradição. Por isso, Ngungunhane afirma: "E terão que voltar ao princípio dos princípios” (BA KA KHOSA, 2013, p. 123).

\section{Considerações finais}

Depois da queda, há uma transformação na personagem Ngungunhane, que, de tirano, se torna um homem com a capacidade de prever fatos do período colonial e do pós-colonial de Moçambique. Ademais, está apto a realizar uma avaliação crítica do pós-independência.

Focalizando o imperador de Gaza, Ungulani Ba Ka Khosa pratica o revisionismo histórico e, assim, questiona a versão dos fatos imposta pelo discurso nacionalista. Este, ao eleger uma visão acerca do passado, nega legitimidade a outras. Tal prática atua a serviço da manipulação da memória coletiva, a qual, como observa Le Goff (1990), sempre foi posta em jogo de forma importante na luta das forças sociais pelo poder. O estudioso alerta, ainda, que 
tornarem-se senhores da memória e do esquecimento é uma das grandes preocupações dos grupos e dos indivíduos, que dominaram e que dominam as sociedades.

A memória é um instrumento de poder porque as suas alterações e perdas determinam modificações na identidade. Esta, para ser autêntica, não pode estar apoiada apenas em uma política, tampouco, segundo Cabaço (2007), assume o perfil dos modelos prescritivos. Apesar disso, em Moçambique, depois da independência, com a mitificação de Ngungunhane e o apagamento da tradição, uma identidade foi forjada. Considerando a uniformização cultural e ideológica o caminho para a unidade nacional, o governo da época resolveu suplantar a tribo para construir a nação. O produto deste procedimento foi, segundo Ba Ka Khosa, um corpo desenraizado.

A consciência em relação aos percalços na trajetória pós-colonial de Moçambique situa Ungulani Ba Ka Khosa naquilo que Appiah (1997) definiu como pós-otimismo. Hamilton (2009), por sua vez, inclui o autor de Ualalapi entre os escritores pós-coloniais, aqueles que encaram o passado enquanto caminho para o futuro. Cabe salientar que o exame do passado, segundo Halbwachs (2006), possibilita que um grupo adquira consciência da sua identidade. É esta consciência do pretérito e do presente - para projetar o futuro - de Moçambique que Ungulani Ba Ka Khosa busca em Ualalapi. Para tanto, também ele volta, através da ficção, ao princípio dos princípios.

\section{REFERÊNCIAS}

APPIAH, Kwame Anthony. Na casa de meu pai. Rio de Janeiro: Contraponto, 1997.

BA KA KHOSA, Ungulani. Ualalapi. Belo Horizonte: Nandyala, 2013.

O passado não se impõe com medidas inquisitórias. Moçambique para Todos, Maputo, 05 fev. 2010. Disponível em:

http://macua.blogs.com/moambique_para_todos/2010/02/o-passado-n\%C3\%A3o-seimp\%C3\%B5e-com-medidas-inquisit\%C3\%B3rias.html Acesso em: 20/03/2015.

. Memórias perdidas, identidades sem cidadania. Revista Crítica de Ciências Sociais, Coimbra, v. 106, 2015. Disponível em: <http://rccs.revues.org/5911\#text>. Acesso em: 18/03/ 2016.

BOUENE, Belizardo. Moçambique: 30 anos depois da independência. Africana Studia, Faculdade de Letras da Universidade do Porto, n.8, 2005. Disponível em http://www.africanos.eu/ceaup/uploads/AS08_069.pdf Acesso em 25/04/2017. 
CABAÇO, José Luís. Moçambique: Identidade, colonialismo e libertação. São Paulo: Editora UNESP, 2009.

CHIZIANE, Paulina. As andorinhas. Belo Horizonte: Nandyala, 2013.

GARCIA, José Luís Lima. O mito de Ngungunhane na ideologia nacionalista de Moçambique. In: TORGAL, Luís Reis. Comunidades imaginadas: nação e nacionalismos na África. Coimbra: Imprensa da Universidade de Coimbra, 2008.

HUTCHEON, Linda. Poéticas do pós-modernismo: História, teoria, ficção. Trad. de Ricardo Cruz. Rio de Janeiro: Imago, 1991.

HALBWACHS, Maurice. A memória coletiva. São Paulo: Centauro, 2006.

HAMILTON, Russell. A literatura dos Palop e a teoria pós-colonial. Via Atlântica, São Paulo, n. 3. p. 12-22, 1999. Disponível em:

<http://www.revistas.usp.br/viaatlantica/article/viewFile/48809/52884>. Acesso em: 17 abr. 2016.

LE GOFF, Jacques. História e memória. Campinas: Editora da UNICAMP, 1990.

LEITE, Ana Mafalda. Oralidades e escritas pós-coloniais: estudos sobre literaturas africanas. Rio de Janeiro: EdUERJ, 2012.

. Nação e narrativa pós-colonial. Lisboa: Edições Colibri, 2012. v. 1.

MATA, Inocência. O pós-colonial nas literaturas africanas de língua portuguesa. In: CONGRESSO INTERNACIONAL DA ASSOCIAÇÃO LATINO-AMERICANA DE ESTUDOS DE ÁSIA E ÁFRICA, 10., 2000, Rio de Janeiro. Anais... Disponível em: <http://bibliotecavirtual.clacso.org.ar/ar/libros/aladaa/mata.rtf>. Acesso em: 15 /03/ 2016.

PADILHA, Laura. Entre voz e letra. Rio de Janeiro: Editora Pallas, 2007.

POLLAK, Michael. Memória e identidade social. Estudos Históricos, Rio de Janeiro, v. 5, n. 10, p. 200-212, 1992. Disponível em:

<http://bibliotecadigital.fgv.br/ojs/index.php/reh/article/view/1941/1080>. Acesso em: 25/01/ 2016.

Memória, esquecimento, silêncio. Estudos Históricos, Rio de Janeiro, v. 2. n. 3, p. 315, 1989. Disponível em:

<http://bibliotecadigital.fgv.br/ojs/index.php/reh/article/view/2278/1417>. Acesso em: $25 / 01 / 2016$

RICOEUR, Paul. A memória, a história, o esquecimento. Campinas: Editora da Unicamp, 2007.

TUTIKIAN, Jane. Ungulani Ba Ka Khosa: o romancista das memórias marginalizadas. Mulemba, Rio de Janeiro, v. 1, n. 11, p. 60-76, 2014. Disponível em: 
<http://setorlitafrica.letras.ufrj.br/mulemba/download/artigo_11_5.pdf>. Acesso em: 10/02/ 2016.

VILHENA, Maria da Conceição. Gungunhana em seu reino. Lisboa: Colibri, 1996. Disponível em:

http://www.macua.org/gungunhana/introducao.html Acesso em 20/03/2017. 